\title{
Use of personalized feedback reports in a blended conceptual modelling course
}

\author{
Daria Bogdanova \\ Research Center for Management Informatics \\ KU Leuven \\ Leuven, Belgium \\ daria.bogdanova@kuleuven.be
}

\author{
Monique Snoeck \\ Research Center for Management Informatics \\ KU Leuven \\ Leuven, Belgium \\ monique.snoeck@kuleuven.be
}

\begin{abstract}
Despite the substantial number of existing publications on conceptual modelling education and feedback, in particular, the perfect balance between the effectiveness of feedback and the costs of the feedback design tailored to the field-specific needs of conceptual modelling remains an unanswered scientific and pedagogical question. The existing educational literature and online courses on conceptual modelling tend to overlook the essential aspects of metacognition and self-regulation in the learning process. The problem of providing feedback is exacerbated by the timeconsuming nature of manual feedback provision and the difficulties of automating the provision of personalized and elaborated feedback. This paper presents an experience report on designing and implementing a learning ontology-based personalized feedback report aimed at raising student selfawareness and self-regulated learning in a university level conceptual modelling course, while the design aims at automation of the feedback provisioning in the near future. It describes the stages of learning report development and provides directions for adapting this type of feedback for various learning settings in conceptual modelling education, in view of potential future automation of report provision.
\end{abstract}

Keywords-Conceptual modelling, education, data modelling, blended learning, formative assessment, formative feedback, learning report

\section{INTRODUCTION}

The importance of feedback in the learning process and its influence on the effectiveness of learning has been proven by a large number of studies both in a traditional learning setting (e.g. [1], [2]) and in blended/online learning (e.g. [3]-[5]). Thus, the current scientific and pedagogical discussion on feedback does not concern a question of whether to provide feedback, but rather the question of how to provide it.

Even though the general principles of feedback provision, such as timeliness and a preference for elaborative over purely corrective feedback, are universal for all disciplines, each subject and each teaching situation require a specific combination of feedback properties. In practice, this means that feedback design is influenced by a number of factors: the field of instruction, the setting, the number of students and the teaching load of the professor, the available tools, and so on, and so forth. All these factors are parts of trade-offs, on which an educator should make a responsible decision - and in many cases, this decision is not fully informed.

Despite the substantial number of existing publications on conceptual modelling education and feedback, in particular (e.g. [6]-[8]), the perfect balance between the effectiveness of feedback and the costs of the feedback design tailored to the field-specific needs of conceptual modelling remains an unanswered scientific and pedagogical question. Prior to exploring the specifics of this balance, it is important to define the "effectiveness of feedback" per se. What feedback can be considered effective? Students' and teachers' perspectives may differ drastically on that matter, especially in a traditional, teacher-centered learning setting. According to Carless [9], teachers tend to believe their feedback is more useful and more detailed than students actually perceive it. Moreover, students and teachers perceive the importance of feedback quite differently, especially in case of formative feedback: while students consider elaborative formative feedback very important to their learning process and believe that provision of model answers is not sufficient, teachers tend to believe that provision of a model answer and corrective feedback is acceptable in the higher education context [10].

In view of the abovementioned concerns, several principles of effective and sustainable feedback practice were formulated in [11]: enhancement of student self-evaluative abilities and promotion of self-directed learning, dialogic interaction with peers and the tutor and technology-assisted dialogue to promote student autonomy and reflection. In particular, this means promoting student self-monitoring, goal setting and planning skills - in other words, self-regulation and metacognitive skills are given the spotlight.

The research presented in this paper is part of a larger scale project aiming at the provisioning of automated personalized feedback. However, before even developing the mechanisms for feedback automation, the feedback itself has to be designed. This paper presents a feedback solution for teaching conceptual modelling in a large class: a personalized feedback report that can be presented to a student as a result of correcting a class diagram design exercise. The report design is aimed at adhering to good pedagogical practices while making it possible to provide the feedback in an automated way. Before automating the feedback, we manually generated reports to have the report's design evaluated by students for its usefulness and intended use according to the technology acceptance model (TAM) [12]. This paper presents the results of that evaluation and outlines the future steps towards its automation. In addition, we provide some statistics on student errors categorized using the newly developed learning ontology for conceptual data modelling.

The remainder of the paper is structured as follows. Section II presents the principles for the report's design. Section III presents the evaluation method while section IV presents the results. Section V discusses the results and compares our approach to existing work on the provisioning of elaborated and/or automated feedback in the context of 
conceptual modelling education. Finally, section VI concludes the paper.

\section{FEEDBACK DESIGN}

\section{A. Hattie and Timperley Feedback Model}

Hattie and Timperley feedback model [13] suggests that effective feedback should answer three main questions: "Where am I going?", "How am I going?" and "Where to next?". The first question is related to the ultimate or intermediate learning goals, the second one - to the student's progress towards the learning goals, while the answer to the third question suggests the student what steps should be taken to improve/proceed in the course.

The proposed method of feedback provision - an individual learning report, the example of which can be found in Appendix A, - allows to answer all these questions in a onepage document generated either manually or automatically based on the errors detected in the student works.

\section{B. Learning ontology}

To provide students with a structured set of learning outcomes, as well as to ensure provision of feedback in accordance with Hattie and Timperley feedback model described above and and with the CaMeLOT educational framework for conceptual modelling [14], the preliminary structure of the learning ontology depicted in Fig. 1 was

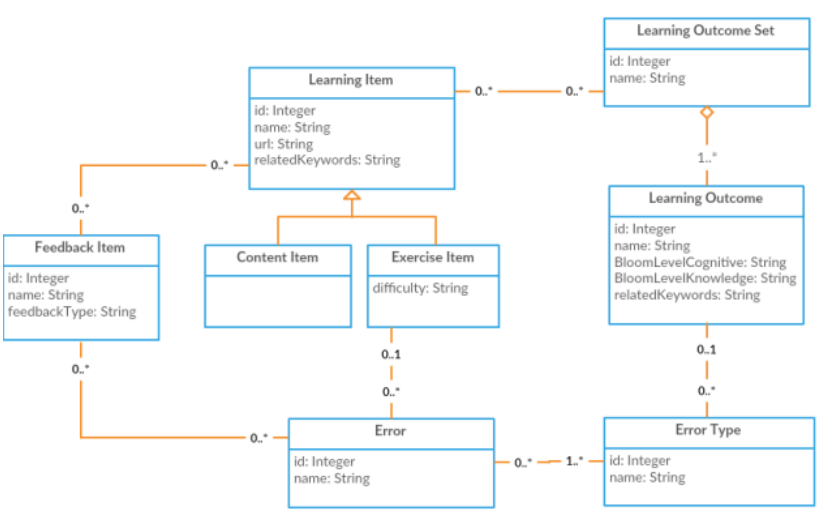

Fig. 1. The preliminary learning ontology structure in UML notation.

developed:

The preliminary learning ontology structure necessary for manual or automated provision of a personalized feedback report consists of the following elements:

- Learning Outcome - a learning outcome to be achieved in a given course module.

- $\quad$ Learning Outcome Set - a set of learning outcomes to be achieved in a given course module

- Learning Item specialized into Content Item (lecture, video, text - non-assessable learning items) and Exercise Item (exercise, homework online quiz assessable learning items). Each learning item is associated with one or many learning outcome sets thus, the learning item is aimed at tackling the learning outcomes in the linked sets.

- Feedback Item - a feedback message or other feedback element given to the student, e.g. "Based on your errors it would be advisable to reread Chapter $\% \mathrm{~N} \%$ of the course book".

- Error - an exercise-specific student error (potential error or those derived from the experience of student works assessment).

- $\quad$ Error Type - a general type of student errors, e.g. "A missing class" or "Wrongly linked association", which can appear in multiple exercise items.

Thus, the following path to feedback provision can be formed, adherent to Hattie and Timperley feedback model.

1) Where am I going?

Classes involved: Learning Outcome, Learning Outcome Set, Feedback Item.

An overview of the intended learning outcomes is provided to the student for the given module of the course. It can be done by a simple listing of the outcomes or using predefined feedback items/indicators that would show which outcomes are already achieved and which still require better proficiency.

\section{2) How am I going?}

Classes involved: Feedback Item, Error, Error Type, Learning Outcome.

For the exercise-specific errors made by the student, the error types are identified. If a student makes one or more errors, the learning outcomes linked to the error types present in the student work are considered not fully achieved: they can be "mostly" achieved in case of a mild error, "partially" achieved in case of a few mild errors or one severe error, or "not yet achieved" in case of several severe errors. Based on the achievement of the learning outcomes from the given outcome set, the student's mark and the corresponding proficiency level in the given course module are determined according to (1):

$$
L_{p}=\sum_{n=1}^{N_{L O}} T_{L O_{n}}-\sum_{m=1}^{N_{E T}} w_{m} N_{E T_{m}}
$$

where $L_{p}$ is the level of proficiency in points (translatable to the verbal levels, such as basic, pre-intermediate, intermediate, upper-intermediate and advanced. Based on the learning outcomes set in the course module and the maximum possible points per learning outcome, the intervals of points correspondent to the proficiency levels can differ), $T_{L O}$ - total points possible for a given learning outcome, $w_{m}$ - the weight of an error of a certain error type, and $N_{E T m}$ - the number of errors of a certain error type that were found in the student work.

Thus, the student receives the following information on his or her progress:

- The list of errors made

- The list of the intended learning outcomes (learning outcome set)

- The level of achievement for each outcome

- The verbal level of proficiency derived from the points falling in the corresponding intervals (e.g., if the sum of total points possible for a learning 
outcome set is 20 , and the module does not cover advanced knowledge related to a certain skill, the interval between 16 and 20 points can be viewed as indicating the "upper-intermediate" level of proficiency).

3) Where to next?

Classes involved: Feedback Item, Learning Item, Learning Outcome, Learning Outcome Set

Based on the error types identified in a student's work and the subsequent identification of the learning outcomes that are not fully achieved, a number of feedback items including the list of recommended learning items corresponding to the addressed learning outcome set can be provided to the student.

\section{Feedback report overview}

The example of a personalized feedback report is provided in Appendix A. The report is structured as follows: first, the students receive some introductory information on what they are going to read. Next, they are provided with the list of key errors made in the requirements analysis and the model itself. Just below the error list, they can find the recommendations on which part of the course text they should reread and which quizzes they should redo to fill in the gaps in their knowledge. Further, they are provided with an overview of their level of achievement of learning outcomes, as well as with their proficiency level indicated on a scale.

The feedback report is provided as a supplementary document to the student work corrected by a teacher.

\section{METHODS}

\section{A. Course and students}

The feedback was provided to the Master level students following the course of Architecture and Modelling of Management Information Systems as part of their formative evaluation. The course teaches enterprise information systems engineering according to MERODE approach [15] and is given in a blended learning format: most of the course materials were accessible through a Small Private Online Course (SPOC), however, life lectures and exercise sessions were also provided to students on campus. As part of the ongoing formative evaluation, the students are given an opportunity to do an optional homework on class diagram design to receive additional feedback and make sure they are on track with the course. The students could choose to work individually or in groups of up to four people.

The total number of students registered in the course was 94. The number of students who submitted the optional homework was 61 , out of which 34 chose to work in groups. Thus, 38 homeworks were analysed and 38 feedback reports were provided to the individual students or groups.

\section{B. The task and student errors identification}

As part of their homework, the students had to design an existence dependency graph in MERODE modelling notation. They were provided with a description of a case (a requirements document) close to a real life context - an insurance company - and were asked first to analyze the requirements document to distinguish the areas of text related to enterprise, IS service and Business process layers, and then to create an existence dependency graph (EDG) that would correspond to the requirements (the full text of the task is provided in Appendix B). The targeted model solution to the homework case is provided in Fig. 2. The purple lines indicate that the given classes or associations were optional, so no points were deduced if the said classes or associations were missing.

The learning outcome set for this homework, as well as the learning items corresponding to each of the learning outcomes, are shown in Table I. It is important to note that

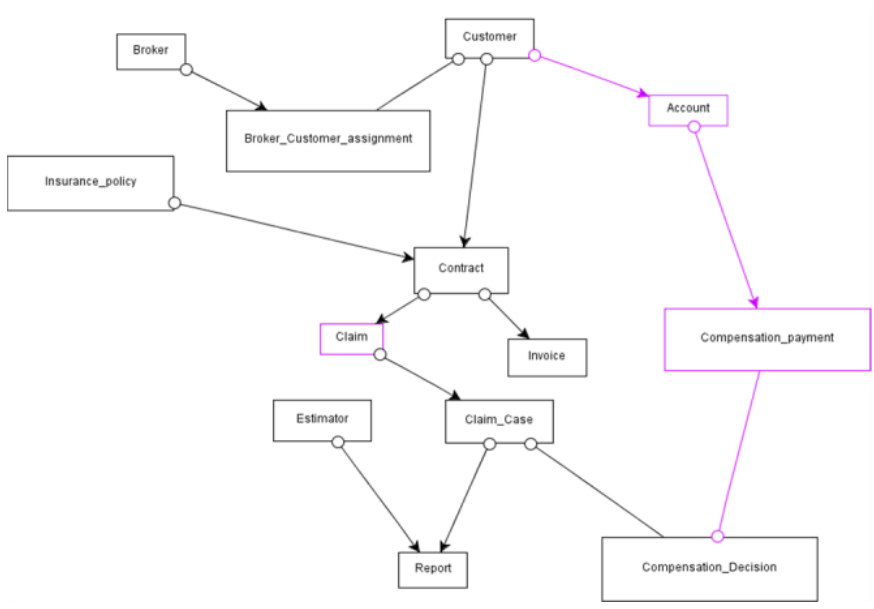

Fig. 2. The model solution in MERODE modelling notation.

the learning outcomes presented in the table are not exhaustive: each of these outcomes has prerequisite outcomes of a lower cognitive level of the revised Bloom's taxonomy [16].

TABLE I. INTENDED LEARNING OUTCOMES FOR HOMEWORK 1 AND THE CORRESPONDING LEARNING ITEMS

\begin{tabular}{|c|c|c|}
\hline $\begin{array}{l}\text { Learn. } \\
\text { outcome }\end{array}$ & The student should be able to: & Learning items \\
\hline LO1 & $\begin{array}{l}\text { distinguish between classes, instances } \\
\text { and events }\end{array}$ & Unit 2.1 \\
\hline LO2 & $\begin{array}{l}\text { identify and eliminate synonyms from } \\
\text { the requirements document }\end{array}$ & $\begin{array}{l}\text { Exercise 2, Quiz } \\
2\end{array}$ \\
\hline LO3 & $\begin{array}{l}\text { analyse the requirements to } \\
\text { distinguish areas of text related to } \\
\text { enterprise layer objects/events, IS } \\
\text { service and Business process layers }\end{array}$ & $\begin{array}{l}\text { Unit 3.2, } \\
\text { Quiz 3 }\end{array}$ \\
\hline LO4 & give meaningful names to the classes & Quiz 4b \\
\hline LO5 & $\begin{array}{l}\text { correctly name all the classes } \\
\text { according to their definitions }\end{array}$ & Quiz 4b \\
\hline LO6 & $\begin{array}{l}\text { find between which classes an } \\
\text { association should be formed }\end{array}$ & Exercise 2 \\
\hline $\mathrm{LO} 7$ & use the association classes correctly & $\begin{array}{l}\text { Exercise 2, } \\
\text { Unit } 4\end{array}$ \\
\hline LO8 & $\begin{array}{l}\text { picture the existence dependency of } \\
\text { classes in the correct order }\end{array}$ & $\begin{array}{l}\text { Unit 3, } \\
\text { Quiz 4a }\end{array}$ \\
\hline LO9 & $\begin{array}{l}\text { translate the requirements correctly } \\
\text { into the association multiplicities }\end{array}$ & Quiz 4a, 4b \\
\hline
\end{tabular}

As described in Section II.B, each learning outcome is associated with a number of error types. Based on the previous examination of similar student works (e.g. reported in [17]), a set of error types was linked to the presented learning outcomes - see Table II. The last error type (E22) does not have a corresponding learning outcome in the given learning outcome set, as its corresponding learning outcome 
- "A student should be able to apply MERODE modelling notation" corresponds to the Factual knowledge level of the revised Bloom's taxonomy, addressed in the previous parts of the course.

TABLE II. ERROR TYPES AND THE CORRESPONDING LEARNING OUTCOMES

\begin{tabular}{|l|l|l|}
\hline ID & Error type & LO \\
\hline E1 & $\begin{array}{l}\text { Wrong layer categorisation in requirements document } \\
\text { analysis }\end{array}$ & LO3 \\
\hline E2 & An enterprise layer event typenot identified & LO3 \\
\hline E3 & An enterprise layer class not identified & LO3 \\
\hline E4 & A business process layer task not identified & LO3 \\
\hline E5 & IS layer class/enterprise layer class confusion & LO3 \\
\hline E6 & $\begin{array}{l}\text { Imposed multiplicity (1 instead of 0..1, or 1 instead of } \\
1 . .\end{array}$ & LO9 - mandatory instead of optional) \\
\hline E7 & Superfluous association & LO6 \\
\hline E8 & A non-meaningful name of a class & LO4 \\
\hline E9 & Missing class & LO1 \\
\hline E10 & Superfluous association class & LO7 \\
\hline E11 & Wrongly linked association & LO6 \\
\hline E12 & An enterprise class is named by its state & LO4 \\
\hline E13 & Missing/unclear definition & LO5 \\
\hline E14 & Wrong direction of existence dependency & LO8 \\
\hline E15 & Missing association & LO6 \\
\hline E16 & Enterprise layer event type/class confusion & LO1 \\
\hline E17 & State/class confusion & LO1 \\
\hline E18 & An IS layer event type/class not identified & LO3 \\
\hline E19 & Missing association class & LO7 \\
\hline E20 & $\begin{array}{l}\text { Superfluous class (a synonym modelled as a separate } \\
\text { class) }\end{array}$ & LO2 \\
\hline E21 & Class/attribute confusion & LO1 \\
\hline E22 & Modelling notation error \\
\hline & & NA \\
\hline
\end{tabular}

The student works were checked manually and each of the errors was entered in a list of exercise-specific errors, and classified into the corresponding error type.

\section{Survey}

After the students were presented with the corrected works and the individual feedback reports, they were asked to complete an anonymous short online survey including one question on the perceived usefulness of the feedback report and one on the intention of use of such reports in this or other courses (5-point Likert scale with neutral opinion in the middle).

Out of the 61 students that submitted the homework, 43 students filled in the survey.

\section{RESULTS}

\section{A. Student errors}

After the careful analysis of the student works, 36 exercise-specific errors were identified, which were then categorized into the 22 error types listed above.

The full list of exercise-specific errors is not provided for the sake of brevity. Below we provide several examples of exercise-specific errors:

Error Type: E11

Error: Wrongly linked association (Policy-Compensation) Error Type: E9

Error: Class is missing (Contract)

The error statistics are presented in Table III, along with the measure of "severity" that was used for the calculation of the mark and the proficiency level (the weight of a "low severity" level was "-1", and the "high severity" was “-2").
TABLE III. ERROR TYPE FREQUENCY IN THE STUDENT HOMEWORKS

\begin{tabular}{|l|l|l|}
\hline Error type code & Severity & Frequency \\
\hline E1 & High & 40 \\
\hline E2 & Low & 36 \\
\hline E9 & High & 36 \\
\hline E4 & Low & 29 \\
\hline E6 & Low & 25 \\
\hline E11 & High & 23 \\
\hline E3 & Low & 20 \\
\hline E7 & Low & 20 \\
\hline E18 & Low & 16 \\
\hline E10 & Low & 13 \\
\hline E8 & Low & 11 \\
\hline E5 & High & 8 \\
\hline E20 & High & 8 \\
\hline E14 & High & 7 \\
\hline E16 & High & 6 \\
\hline E17 & High & 6 \\
\hline E22 & High & 6 \\
\hline E19 & High & 5 \\
\hline E15 & High & 4 \\
\hline E13 & Low & 2 \\
\hline E21 & High & 2 \\
\hline E12 & Low & 1 \\
\hline & & \\
\hline
\end{tabular}

\section{B. Student perception of feedback}

The overall perception of feedback report usefulness (or helpfulness, as it was formulated in the survey), as well as the intention of use were very high among the survey participants. As it can be seen in Fig. 3. Perceived helpfulness and intention of use survey results, the majority of the participants indicated that they would like to receive similar learning reports for the same course or other courses in their program. Similarly, the majority of the students find the feedback reports either helpful or very helpful, with about one quarter of the students that were unsure whether the feedback reports were helpful or not. None of the survey participants indicated that they consider the feedback reports not helpful or that they would not want to receive such reports in the future.

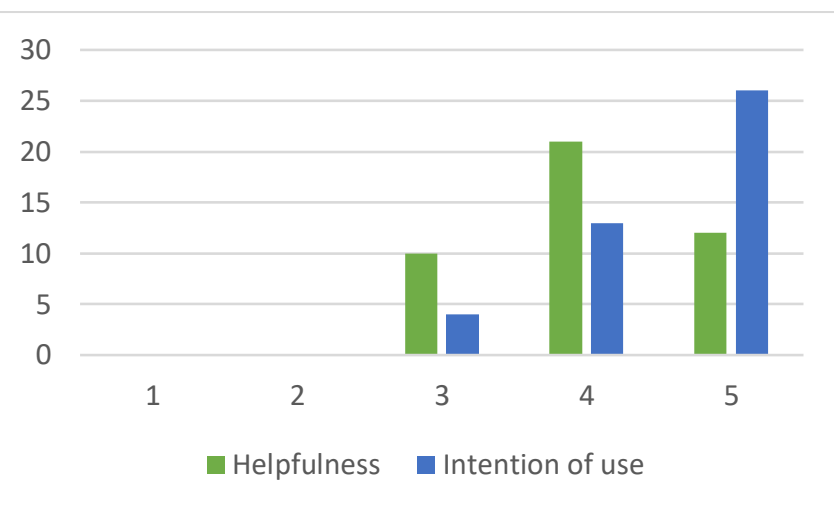

Fig. 3. Perceived helpfulness and intention of use survey results.

The median overall acceptance score (the sum of helpfulness and the intention of use) was as high as 9, with only two students choosing the "neutral" answer for both of the questions (6).

It is also important to note that there was a very weak negative correlation (-0.14) between the mark received by the students and the overall acceptance score for the feedback reports. 


\section{DISCUSSION}

In this work, we presented experiences from using ontology-based personalized experience reports in a conceptual modelling course. While designing the reports, we tried to adhere to the principles of effective feedback presented in [11] and [13], and, at the same time, open a path for future feedback automation.

In search for an answer to the question whether those principles already applied in the current conceptual modelling pedagogy, the authors found that the existing literature on this issue is scarce. The recent analysis of a sample of learning materials on conceptual data modelling showed that metacognitive knowledge level is not represented in any of the analysed textbooks, massive open online courses (MOOCs) or university exams [18]. There is a small number of papers reporting various types of automated feedback for conceptual modelling education, which involve students in a "technology-assisted dialogue". For example, a tool for creating UML class diagrams developed in [19] employs a virtual conversational agent and provides students with hints and solution evaluation based on the affective states, frustration and previous activities. Another intelligent tutoring system for teaching UML class diagrams uses a hint sequencing ranging from a reminder to a detailed explanation, based on student actions, knowledge level and learning style [20]. However, to this moment, none of the papers reporting on feedback automation for conceptual modelling describe the structure of the learning ontology or a similar underlying model in detail and provide an instantiation of such a model.

The error statistics shows that the novice modelers' most common errors in the simple class diagram task are related to the initial misinterpretations of the requirements at the stage of requirements analysis. These errors could possibly lead to the more severe errors later on, such as missing classes and associations, as well as multiplicity errors (in line with [17], [21], [22]). The learning ontology for error categorization and the linking of errors and error types to the corresponding learning outcomes of the course or module could be potentially used for designing new learning material that would help the students overcome the most common difficulties on conceptual data modelling.

According to the results of the student survey, the overall acceptance of the new form of feedback among students was very high: there was no negative opinions neither on the helpfulness nor on the intention of use of such reports. The mark received by the students also did not seem to influence their opinion on the helpfulness of feedback. Nevertheless, several limitations should be taken into account: not all the students that received the feedback reports participated in the survey, and the number of students was quite small. However, the students participated in the survey represent the majority of the group of interest, and include representatives of most student groups that submitted the homework.

\section{CONCLUSION AND FUTURE WORK}

This paper reports on the design of a learning ontologybased personalized feedback report aimed at raising student self-awareness and self-regulated learning. The feedback report makes use of a learning ontology that connects learning items, learning objectives and errors. This allows to provide the feedback according to Hattie and Timperley's feedback model. The feedback report was well-received by the students.

The next path of research is the exploration of automatic generation of feedback reports based on the established learning ontology and the perception of such automatically generated feedback reports by the students. In the future, the academic efficiency of such feedback reports should be explored, as well as the presence of action of students on the feedback.

\section{REFERENCES}

[1] R. Vollmeyer and F. Rheinberg, “A surprising effect of feedback on learning," Learn. Instr., vol. 15, no. 6, pp. 589-602, Dec. 2005 .

[2] A. Poulos and M. J. Mahony, "Effectiveness of feedback: the students' perspective," Assess. Eval. High. Educ., vol. 33, no. 2, pp. 143-154, Apr. 2008.

[3] U. M. Krause, R. Stark, and H. Mandl, "The effects of cooperative learning and feedback on e-learning in statistics," Learn. Instr., vol. 19, no. 2, pp. 158-170, 2009.

[4] J. W. Gikandi, D. Morrow, and N. E. Davis, "Online formative assessment in higher education: A review of the literature," Comput. Educ., vol. 57, no. 4, pp. 2333-2351, Dec. 2011.

[5] F. M. Van der Kleij, R. C. W. Feskens, and T. J. H. M. Eggen, "Effects of Feedback in a Computer-Based Learning Environment on Students' Learning Outcomes: A MetaAnalysis," Rev. Educ. Res., vol. 85, no. 4, pp. 475-511, Dec. 2015.

[6] G. Sedrakyan, J. De Weerdt, and M. Snoeck, "Process-mining enabled feedback: "tell me what i did wrong' vs. "tell me how to do it right,"” Comput. Human Behav., vol. 57, pp. 352-376, 2016.

[7] N. Bolloju and F. S. K. Leung, "Assisting novice analysts in developing quality conceptual models with UML," Commun. ACM, vol. 49, no. 7, pp. 108-112, Jul. 2006.

[8] D. R. Stikkolorum, T. Ho-Quang, B. Karashneh, and M. R. V Chaudron, "Uncovering Students' Common Difficulties and Strategies During a Class Diagram Design Process: an Online Experiment,"in EduSymp@MoDELS, 2015.

[9] D. Carless, "Differing perceptions in the feedback process," Stud. High. Educ., vol. 31, no. 2, pp. 219-233, Apr. 2006.

[10] J. Perera, N. Lee, K. Win, J. Perera, and L. Wijesuriya, "Formative feedback to students: the mismatch between faculty perceptions and student expectations," Med. Teach., vol. 30, no. 4, pp. 395-399, Jan. 2008.

[11] D. Carless, D. Salter, M. Yang, and J. Lam, "Developing sustainable feedback practices," Stud. High. Educ., vol. 36, no. 4, pp. 395-407, Jun. 2011.

[12] F. D. Davis, "Perceived Usefulness, Perceived Ease of Use, and User Acceptance of Information Technology," MIS Q., 1989.

[13] J. Hattie and H. Timperley, "The power of feedback," Rev. Educ. Res., vol. .77, no. 1, pp. 16-7, Mar. 2007.

[14] D. Bogdanova and M. Snoeck, "CaMeLOT: An Educational Framework For Conceptual Data Modelling," Inf. Softw. Technol., Feb. 2019.

[15] M. Snoeck, Enterprise Information Systems Engineering: The MERODE Approach. Springer Publishing Company, Incorporated, 2014.

[16] D. R. Krathwohl, “A Revision of Bloom's taxonomy,” Theory Into Pract., 2002.

[17] D. Bogdanova and M. Snoeck, "Learning from errors: Errorbased exercises in domain modelling pedagogy," in Lecture Notes in Business Information Processing, 2018, vol. 335, pp. 321-334.

[18] D. Bogdanova and M. Snoeck, "Domain modelling in bloom: Deciphering how we teach It," in Lecture Notes in Business Information Processing, 2017

[19] P. S. Inventado, R. Legaspi, T. D. Buy, and M. Suarez, "Predicting Student' s Appraisal of Feedback in an ITS Using Previous Affective States and Continuous Affect Labels from EEG Data," Proc. 18th Int. Conf. Comput. Educ., 2010.

[20] S. M. Parvez and G. D. Blank, "Individualizing Tutoring with Learning Style Based Feedback," in Intelligent Tutoring Systems, Berlin, Heidelberg: Springer Berlin Heidelberg, 2008, pp. 291301.

[21] D. Batra and S. R. Antony, "Novice errors in conceptual database 
design,” Eur. J. Inf. Syst., vol. 3, no. 1, pp. 57-69, Jan. 1994.

F. Leung and N. Bolloju, "Analyzing the Quality of Domain

Models Developed by Novice Systems Analysts," in Proceedings

of the 38th Annual Hawaii International Conference on System

Sciences, pp. 188b-188b. 


\section{FEEDBACK REPORT 1 - HOMEWORK 1 - Insurance Company EDG}

Here is some background information to help you understand this report better:

This exercise has been designed to test your achievements of intermediate learning goals of the course and to help identify the possible gaps in your knowledge.

To do so, we categorize all the errors made in the model according to the knowledge and cognitive levels identified in the Revised Bloom's Taxonomy of educational objectives. Below, you will find the list of key errors made in the requirements analysis and the model itself and some recommendations for improvement of the modelling skills.

\section{Requirements analysis}

- A business process layer event listed as enterprise layer event

- An enterprise layer event not identified

- A business process layer event not identified

EDG

- Superfluous class "Profile" - IS/BP object listed as class

- Imposed multiplicity ( 1 instead of $0 . .1$, or 1 instead of $\left.1 . .^{*}\right)$

- Superfluous association "Invoice-Customer": the customer is already connected to the invoice through contract.

- A non-meaningful name of a class (“Assigned_to")

These errors indicate that you might need to reread Units 2.1, 3.2.3 and 4.2.3 of the course book and review the following exercises: Quiz 2, Quiz 3 and Exercise session 2 in the online course.

\section{Your level of achievement of learning outcomes:}

\begin{tabular}{|l|c|}
\hline You are able to distinguish between classes, instances and events & + \\
\hline You are able to identify and eliminate synonyms from the requirements document & + \\
\hline $\begin{array}{l}\text { You are partially able to analyse the requirements to distinguish areas of text related to } \\
\text { enterprise layer objects/events, IS service and Business process layers }\end{array}$ & +- \\
\hline You are mostly able to identify the classes correctly from the requirements document & ++- \\
\hline You are mostly able to give meaningful names to the classes & ++- \\
\hline You are able to correctly name all the classes according to their definitions & + \\
\hline You are mostly able to find between which classes an association should be formed & ++- \\
\hline You are able to picture the existence dependency of classes in the correct order & + \\
\hline $\begin{array}{l}\text { You are partially able to translate the requirements correctly into the association } \\
\text { multiplicities }\end{array}$ & +- \\
\hline
\end{tabular}

Your current expertise level in creating EDGs:

\begin{tabular}{|l|l|l|l|}
\hline & & & \\
\hline Basic & Pre-Intermediate Intermediate & Upper-intermediate Advanced
\end{tabular}

P.S. This exercise per se allows you to reach upper-intermediate level at max. 


\section{Homework 1 Case Description}

Alpha Insurance is an insurance company that provides its clients with various types of insurance policies.

As soon as a customer addresses Alpha Insurance, a broker is assigned to follow the customer's file. The broker is registered in the system, so that when a customer calls, based on the contract, the help desk can immediately trace who is the customer's first account manager. The customer indicates which type(s) of insurance policy they would like to sign for, so the broker could, depending on the case, either assess the customer's profile on the spot or send the customer's file for analysis to the head office. After the customer's profile analysis, a preliminary offer on an insurance product is made to the customer either in person or by email. If the customer agrees to the offer, a contract is generated and signed by both parties. Afterwards, the client is invoiced (monthly or yearly - depending on the choice made in the contract) according to the price of the insurance product they bought.

In case the insured event happens, a customer should send a claim for compensation. Then the company opens a claim case and transfers it for assessment by the estimator. According to the report issued by the estimator, the sum of compensation is calculated. Afterwards, the compensation is paid to the customer's account. The estimators' reports must be stored in the database for at least one year after the payment of compensation for legal purposes.

Create the EDG for this case and provide a definition for each object type. 